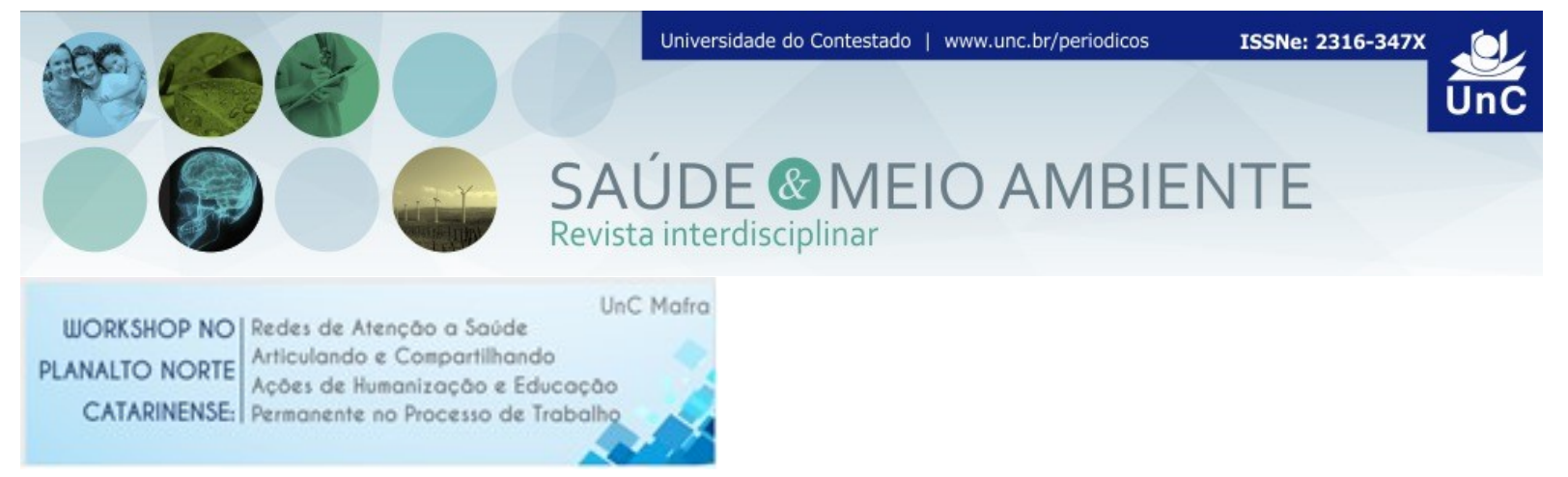

\title{
A EDUCAÇÃO PERMANENTE COMO ESTRATÉGIA TRANSFORMADORA NA PREVENÇÃO DO SUICÍDIO ${ }^{1}$
}

\author{
Ariane Woehl ${ }^{2}$ \\ Debora Popadiuk ${ }^{3}$
}

\section{RESUMO}

INTRODUÇÃO: Falar da morte, sendo esta uma condição natural da vida, e refletindo sobre as circunstâncias que envolvem o suicídio, revela-se a necessidade de debruçar o olhar, diante a este fenômeno histórico, social e absolutamente individual. Os reflexos dos cenários de violência são conhecidos em muitos níveis de Atenção em Saúde. Porém, não são notórios como estas Violências externas, impactam a vida diária de uma sociedade. Botega (2006) afirma que o suicídio está entre as dez principais causas de morte na população mundial em todas as faixas etárias. OBJETIVO: Fomentar em Mafra, estratégias de Prevenção do Suicídio, através da Educação Permanente. MATERIAL E MÉTODOS: A partir do cenário observado em Mafra/SC dos elevados números de tentativas de suicídios, e suicídios exitosos, comparados aos indicadores nacionais, delinearam-se junto ao Plano Municipal de Saúde 2014-2017, estratégias com ações e metas definidas, que atingissem estes indicadores, objetivando diminuí-los. Iniciou em Mafra/SC então, em 2014, capacitações em formato de Educação Permanente, os Seminários Municipais, com a temática da Prevenção ao Suicídio, de maneira anual com os profissionais da Rede Municipal de Saúde, bem como outros serviços envolvidos na rede de cuidados e atenção a esse público alvo. É preciso saltar os olhos frente ao fenômeno silencioso do suicídio que ocorre na sociedade e, sobretudo, se preocupar de que forma, os profissionais de saúde, poderão identificar sinais de alerta, utilizar o acolhimento, e o

\footnotetext{
${ }^{1}$ Fundo Municipal de Saúde.

2 Graduada em Serviço Social pela Universidade do Contestado (1998). Pós-graduada em Gestão de Pessoas-UnC Canoinhas 2001. Pós-graduada em Gerenciamento de Unidades Básicas de SaúdeGERUS-Escola de Saúde Pública de SC.2008 Especialista em Impactos da Violência na Saúde. FIOCRUZ-2014. Pós-graduada Gestão em Saúde Pública-UnC Mafra/SC-2014/2016 Cursando CERP/SC- Centro de Estudos em Reparação Psíquica de Santa Catarina. Como lidar com os efeitos psicossociais da violência? Instituto APPOA (Associação Psicanalítica de Porto Alegre), no âmbito do Projeto Clínicas do Testemunho, financiado pela Comissão de Anistia, órgão do Governo Federal Brasileiro, e pelo Newton Fund. Assistente Social Secretaria Municipal de Saúde Mafra/SC. Santa Catarina. Brasil. E-mail: arianewoehl@gmail.com

3 Psicóloga pela Universidade do Contestado. Pós-Graduada em Saúde Coletiva pela Faculdade Unyleya. Com experiência de estágio em triagens na saúde pública, estágio na área clínica com enfoque na Terapia Relacional Sistêmica e na área organizacional com trabalho voltado ao desperdício em uma Instituição Hospitalar. Psicóloga integrante do Núcleo de Apoio à Saúde da Família (NASF) da secretaria Municipal de Saúde Mafra/SC. Santa Catarina. Brasil. E-mail: psicologa deborapopadiuk@yahoo.com
} 
encaminhamento seguro das pessoas que tentaram o Suicídio, bem como os sobreviventes. Baseia-se o entendimento, de que há uma necessidade significativa de sensibilização ao assunto dentro dos serviços de saúde, como um recurso inicial de discussão, para fomentar um acolhimento diferenciado, dentro das instituições públicas. RESULTADOS: A partir dos seminários, observou-se que os profissionais de saúde, estão a cada ano, mais qualificados e seguros para identificarem sinais de alerta, atenderem os casos e darem os devidos encaminhamentos. Os usuários com históricos de tentativas de suicídio podem ser monitorados pela equipe de atenção básica, conforme o Ministério da Saúde instituiu em 2006, nas Diretrizes Nacionais para Prevenção do Suicídio. Aponta-se também, ações dentro da Rede de Saúde Mental nas rotinas de trabalho, onde se definiu, de maneira significativa, o acolhimento, a atenção aos sinais de alerta frente a um risco para o suicídio, bem como, a inserção destes casos de maneira abreviada aos serviços de apoio, especializados e de monitoramento. Efetivou-se também, um estreitamento entre os serviços Pronto Atendimento Municipal, Serviço Social, CAPS, NASF, Vigilância Epidemiológica, Ambulatório de Psiquiatria, Atenção básica, a partir das notificações de tentativas de suicídios, e demandas livres, que são resgatadas nos serviços de saúde, propiciando diálogo, troca de experiências e ampliação do conhecimento sobre o suicídio, tentativas de suicídios e suas consequências, conforme prevê a Rede de Atenção Psicossocial-RAPS, através da Portaria n³.088 de 23/12/2011 (BRASIL, 2011). Implantou-se também, no início de 2016, o Grupo de Amparo a Vida-GAV, que tiveram como mentoras, assistente social da Policlínica Municipal de Saúde, bem como psicóloga do NASF, que desenvolveram de maneira permanente reuniões técnicas de trabalho, a cada semestre, sinalizando pontos a serem ajustados na rede Municipal de Saúde, frente à Prevenção ao Suicídio. Outra proposta do GAV é acolher de maneira espontânea, os usuários (que tentaram suicídio) que estão sendo atendidos por diferentes serviços municipais, e que, a partir de um contato telefônico são convidados a participarem mensalmente de um grupo de apoio, onde a finalidade é o acolhimento coletivo, assegurando um espaço de escuta qualificada e o despertar para um espaço de pertencimento, diante do seu sofrimento mental. Prática esta inspirada na literatura: "Telefonemas na Crise. Percursos e Desafios na Prevenção ao Suicídio" (BOTEGA, 2010). Outro grupo do GAV é voltado aos sobreviventes de um suicídio exitoso, que são os familiares que perderam seus entes, por suicídio que se reúnem em horário diferenciado, para receberem apoio e escuta ativa. Através da Secretaria Municipal de Saúde foram construídos materiais de apoio aos profissionais de saúde, sendo o Manual de Bolso, que apresenta fundamentos essenciais na prevenção ao suicídio, além do Manual de Prevenção ao Suicídio voltado à comunidade, alertando os riscos para as tentativas de suicídio, sinais de alerta, assim como quebrando mitos e tabus que balizam o suicídio. Difundir o fenômeno do suicídio, nos Serviços de Saúde, através da Educação Permanente, com os Seminários Municipais de Prevenção do Suicídio, foi o início de um trabalho exitoso na rede pública de Saúde de Mafra/SC. Desta forma, enfrentar-se-á este fenômeno embaraçoso e certamente espinhoso para muitas pessoas, deixando de ser silencioso e passando a ser efetivamente evitável. Os trabalhadores de Saúde, capacitados e atentos aos cenários explorados, com suas práticas diárias, estão contribuindo significativamente na melhoria da qualidade de vida das pessoas, estando estas doentes, moribundas e/ou em sofrimento mental. CONCLUSÕES: Refletir sobre os acidentes e as violências externas, se torna uma tarefa para todos os profissionais de saúde. Buscar enquadrar-se neste contexto, inserindo os profissionais da Rede de 
Saúde Municipal, como atores de ações modificadoras de enfrentamento as causas e cuidado das vítimas, primando à promoção e o cuidado à saúde mental, deve ser a bandeira de Mafra/SC. Os Seminários Municipais de Prevenção ao Suicídio despertaram a atenção dos Trabalhadores da Saúde, quebrando o silêncio que marca o suicídio em Mafra/SC, bem como os sensibilizando e os qualificando a cada ano ao acolhimento das pessoas em sofrimento mental.

Palavras-chave: Suicídio. Prevenção. Saúde.

\section{REFERÊNCIAS}

BARRERO, S.P.; CORREA, H. Suicídio uma morte evitável. São Paulo: Editora Atheneu, 2006.

BOTEGA, N. J. Prevenção do comportamento suicida. PSICO, Porto Alegre, PUCRS, v. 37, n. 3, p. 213-220, set./dez. 2006.

BRASIL. Portaria $n^{\circ}$ 1876, de 14 de agosto de 2006. Institui Diretrizes Nacionais Para Prevenção do Suicídio, A Ser Implantadas em Todas As Unidades Federadas, Respeitadas As Competências das Três Esferas de Gestão. Brasília, Disponível em: <http://bvsms.saude.gov.br/bvs/saudelegis/gm/2006/prt1876_14_08_2006.html>. Acesso em: 17 nov. 2017.

BRASIL. Portaria $\mathrm{n}^{\circ} \mathbf{3 0 8 8}$, de 23 de dezembro de 2011. 2011. Brasília, 26 dez. 2011. Seção 1, p. 230-232. Disponível em: <http://bvsms.saude.gov.br/bvs/ saudelegis/gm/2011/prt3088_23_12_2011_rep.html>. Acesso em: 17 nov. 2017.

Resumo recebido em: 12/12/2017

Resumo aprovado em: 17/12/2017

Resumo publicado em: 20/12/2017 